\title{
Controversies in Electrophysiology
}

Editors

EMILE G. DAOUD

RAUL WEISS

\section{CARDIAC \\ ELECTROPHYSIOLOGY CLINICS}

www.cardiacEP.theclinics.com

Consulting Editors

RANJAN K. THAKUR

ANDREA NATALE

September 2015 • Volume 7 • Number 3 